\title{
Chemical Components of Noncommercial Alcohol Beverage Samples: A Study With the Viewpoint of Toxic Components in Mashhad, Iran
}

\author{
Bita Dadpour, ${ }^{1}$ Arya Hedjazi, ${ }^{2}$ Hamideh Ghorbani, ${ }^{2,}{ }^{*}$ Hamid Khosrojerdi, ${ }^{1}$ Seyed Mohsen Vaziri, ${ }^{3}$ Haleh \\ Malek Zadeh, ${ }^{4}$ and Amir Habibi Tamijani ${ }^{2}$ \\ ${ }^{1}$ Faculty of Medicine, Addiction Research Center, Mashhad University of Medical Sciences, Mashhad, IR Iran \\ ${ }^{2}$ Legal Medicine Research Center, Legal Medicine Organization, Tehran, IR Iran \\ ${ }^{3}$ Cardiac Anesthesia Research Center, Mashhad University of Medical Sciences, Mashhad, IR Iran \\ ${ }^{4}$ Medical Toxicology Research Center, Mashhad University of Medical Sciences, Mashhad, IR Iran \\ "Corresponding author: Hamideh Ghorbani, Legal Medicine Research Center, Legal Medicine Organization, Tehran, IR Iran. Tel: +98-9153052242, Fax: +98-5138454400, E-mail: \\ dr.h.ghorbani@gmail.com
}

Received 2015 February 09; Revised 2015 March 15; Accepted 2015 April 12.

\begin{abstract}
Background: Iran has one of the lowest alcoholic beverage use rates in comparison with other countries, because it is legally forbidden and because of religious beliefs. Even so, unrecorded and noncommercial alcohol remains a considerable concern, which needs special attention.

Objectives: In the current research, we have studied the general composition of noncommercial alcohol samples to identify potentially toxic components in the context of the city of Mashhad in IR Iran.

Patients and Methods: Using a descriptive study, chemical composition records of alcohol samples obtained from Mashhad and its suburbs (from March 2013 to March 2014) were evaluated in terms of ethanol percentage and methanol percentage using gas chromatography. Likewise, the $\mathrm{pH}$ of the alcohol and the location of the sample were also considered. Some substances, such as inorganic elements, were not included because there was no information about these substances in the records.

Results: Of 877 reports of alcohol samples, more than $50 \%$ were obtained from Mashhad and the rest were from the suburbs. Of the reports, $57.5 \%$ were in the spring and summer, followed by $42.5 \%$ in the fall and winter. The mean (min-max) of ethanol percentage was $30.04 \%$ ( 0 - 98.4). In four cases, methanol was detected. The mean (min-max) of methanol percentage was $23 \%$ (4 - 95).The majority of the samples had an acidic $\mathrm{pH}$.

Conclusions: The composition of unrecorded samples did not raise major toxicological concern beyond ethanol in alcohol products. However, concentration levels of methanol in some unrecorded alcohol samples made these samples detrimental for human consumption.
\end{abstract}

Keywords: Alcoholic Beverages, Chemical, Components, Ethanol, Methanol

\section{Background}

The net effect of alcohol consumption on health is detrimental, with an estimated $3.8 \%$ of all global deaths and $4.6 \%$ of global disability-adjusted life-years attributable to alcohol (1). Alcohol consumption is linked to long-term health and social consequences through three intermediate mechanisms: intoxication, dependence and direct biological and toxic effects (2). In addition to the volume and patterns of drinking, alcohol quality may also have an impact on health issues $(2,3)$. In most regions of the world, the legal availability of alcohol is generally accepted to be one of the primary controls on levels of alcohol consumption and expected harms. Licensing systems are, therefore, a key component of an overall alcohol control policy.

In Iran, alcohol consumption is forbidden due to legal and religious grounds, and alcoholism is not considered a major public health concern. Despite this prohibition, alcoholic beverages are made and sold illegally in Iran. Hence, noncommercial and unrecorded alcohol remains a considerable concern that needs intelligent and realistic policy options. Generally, the consumption of noncommercial alcohol (i.e., homemade alcoholic beverages) among individuals in the lower classes of the population is higher than individuals in the upper classes, who normally are able to have access to commercial alcohol. There have been persistent claims that consumption of unrecorded alcohol causes harm due to toxic ingredients other than ethanol (3). The problem of inadmissible methanol in noncommercial alcohol samples is noticeable. Roughly, less than $0.1 \%$ of the global alcohol-attributed deaths are due to methanol (corresponds to 2,740 deaths based on the global burden of disease) (3, 4). Other than methanol, 
there are other potential toxic effects of noncommercial alcohol samples due to ingredients other than ethanol. Recently, concerns have been raised about the higher levels of alcohols in noncommercial alcohol (5). There is also a continuing discussion on the presence of lead in noncommercial alcohol (6). In addition to methanol and lead poisonings, ethylene glycol, polyhexamethylene guanidine (PHMG) and acetaldehyde have occasionally been a concern $(7,8)$. Several cases of methanol poisoning due to noncommercial alcohol consumption were recorded during the last decade. However, there is no literature on the composition of noncommercial beverages in Iran. The forensic toxicology laboratory in the Mashhad legal medicine organization, as a major laboratory center in the east of Iran, provides routine analytical toxicology testing, and a large number of samples are accepted regularly for analysis. This paper presents results of chemical composition and potential harm analysis in obtained unrecorded alcohol samples from the context of the city of Mashhad in Iran.

\section{Objectives}

The purpose of our study was to identify potentially toxic components in noncommercial alcoholic beverages in the context of the city of Mashhad in IR Iran.

\section{Patients and Methods}

All samples $(\mathrm{n}=887)$ were collected during law enforcement by the police in Mashhad and the suburbs between March 2013 and March 2014 and submitted to a legal medicine organization. Methanol and ethanol levels in the alcoholic beverages were determined through direct injection gas chromatography with a flame-ionization detector (GC-FID) method. Regarding the legal medicine organization rules, alcoholic samples were identified by a number, and the analyst was not aware of the content of the samples.

\section{Results}

In total, 887 samples were under study; more than 50\% of samples were obtained from Mashhad and the rest were from suburbs. Of the samples, $32.5 \%$ were obtained in the spring, followed by $24.8 \%$ in the summer, $22.4 \%$ in the fall and $20.1 \%$ in the winter. The percentage of ethanol in our study was divided into three groups. As can be seen in Table 1 , in just a few of the samples, the percentage of ethanol was more than $60 \%$, whereas in a significant proportion (59.8\%) of the samples the ethanol percentage was between $31 \%$ $60 \%$, and a noticeable proportion (38.5\%) was less than $30 \%$.
To sum up, the ethanol percentage in the samples ranged from $0 \%$ to $98.4 \%$, with an average percentage of $30.04 \%$.

In the total of 877 samples, four cases of methanol were detected. The mean of the methanol percentage was $23 \%$. As outlined in Table 2, the results for the $\mathrm{pH}$ of the alcoholic samples are divided into five groups. It is evident that the overwhelming majority of samples have an acidic $\mathrm{pH}$.

\begin{tabular}{lc} 
Table 1. Ethanol Percentage $(\mathrm{V} / \mathrm{V})$ in Noncommercial Alcoholic Samples \\
\hline Percentage of Ethanol & Frequency (\%) \\
\hline Less than 30\% & 38.5 \\
$\mathbf{3 1} \%$ - 60\% & 59.8 \\
\hline More than 60\% & 1.7 \\
\hline & \\
\hline Table 2. pH of Noncommercial Alcoholic Samples & \\
\hline pH of Alcoholic Beverage & Frequency (\%) \\
\hline Less than 4 & 9.1 \\
\hline $\mathbf{4}$ & 44.5 \\
\hline $\mathbf{5}$ & 3.9 \\
$\mathbf{6}$ & 29.3 \\
\hline $\mathbf{7}$ & 13.2 \\
\hline
\end{tabular}

\section{Discussion}

About 30\% of global alcohol consumption comes from unrecorded sources, but there are huge regional differences (9). In consideration of the legal prohibition of alcohol production and consumption in Iran, illegally produced and smuggled alcohol remains a considerable concern.

Noncommercial alcoholic beverages seem to be that which is affordable for alcohol consumers. However, published data on the chemical composition of noncommercial alcoholic beverages is scarce in Iran. The percent of alcohol by volume is now the harmonized measurement for alcohol strength (8). The accurate and rapid determination of ethanol in alcoholic beverages is very important for safety and economic reasons $(8,10)$. Some studies have shown that the unrecorded alcoholic beverages have higher ethanol levels than those that are commercially available (3). The obvious example is the ethanol percent of illegal alcohol products in Russia, which has created public health concerns relating to the consumption of unrecorded alcohol, and are due mainly to the ethanol content $(11,12)$. Even so, in many studies a majority of unrecorded beverage samples had a uniform alcohol content 
of around $40 \%$ by volume and a tiny minority had more than $60 \%$ by volume, which is similar to the commercial alcohols $(3,13,14)$. In the current study, volume percentage of ethanol in a noticeable proportion of the samples (roughly three out of five) was $31 \%-60 \%$ and in a negligible proportion (1.7\%) was more than $60 \%$. Comparing the current study with the others in the context of ethanol percentage, a similar pattern was seen in our samples. Regarding the toxicological point of view, it is not a warning for public health, but it is certainly important to identify the practical consequences of these illegal alcohols, such as the short-term consequences (e.g., unintentional injuries and deaths, suicide, violent behavior) and the long-term problems (e.g., liver cirrhosis, cardiovascular disease, mental problems and cancers). It is impossible to argue against the fact that the vast majority of alcohol-related deaths are due to ethanol $(1,14,15)$. Data about all the potentially presenting compounds in unrecorded alcohol reveals the substantial acute toxic effects of methanol. The current European Union limit for naturally occurring methanol in alcoholic drinks is $0.4 \%$ by volume for methanol at $40 \%$ by volume for alcohol $(16,17)$.

It should be noted that the methanol content would need to exceed $2 \%(\mathrm{v} / \mathrm{v})$ for toxic harm (16). In the current study, methanol was detected in only four cases of the samples, however, all of the four cases exceeded the methanol percent limit for toxicity (more than $2 \%$ ), and the mean of the methanol percentage was $23 \%$. There is no doubt that toxic effects are expected in the four cases, although we did not have access to objective evidence about the practical consequences of consumption based on the records; nevertheless, serious emphasis on prevention is necessary.

About three out of five alcoholic samples were obtained in spring and summer. It is interesting to note that higher alcohol consumption in these two seasons is mentioned in some other studies as well $(18,19)$. On one hand, noncommercial alcoholic beverage production, sale and consumption has no seasonal rhythm; on the other, it seems that alcohol users in our study are occasional rather than regular users. However, more study is needed to investigate the many unanswered questions regarding the impact of the seasons and weekdays on the sale and consumption of noncommercial alcoholic beverages.

There is a clear trend in $\mathrm{pH}$ of the samples, $\mathrm{pH}$ in just over three quarters of the samples was in the range of four to six. Total acidity in alcoholic beverages is initially due to the presence of volatile acids, such as acetic acid or tartaric acid, and dictates the chemical processes taking place in alcoholic beverages $(10,20)$. In the current research, we have studied the general composition of noncommercial alcohol samples. A more pervasive approach is required for other compounds (e.g., higher alcohols, metals, acetalde- hyde, ethyl carbamate, diethyl phthalate). Annually, there are many cases admitted to the medical toxicology center of Mashhad because of methanol poisoning due to homemade alcohol consumption.

To conclude, the current study presents results from the chemical composition analysis and expected potential harm from noncommercial alcohol in Mashhad and its suburbs. This investigation provides inadequate evidence to infer the influence of noncommercial alcohol composition on alcohol-related clinical toxic effects over the effects of ethanol. We detected a relatively high percentage of methanol in four samples, and it is important to emphasize that detailed future research should focus on the other potential components in unrecorded alcohol.

\section{Acknowledgments}

We wish to express gratitude to the Iran legal medicine organization for continuous support. Furthermore, we gratefully acknowledge all the valuable experts in the Mashhad legal medicine organization for their helpful advice.

\section{Footnotes}

Authors' Contribution: Study concept and design: Hamideh Ghorbani and Bita Dadpour; analysis and interpretation of data: Hamideh Ghorbani, Bita Dadpour and Amir Habibi Tamijani; drafting of the manuscript: Seyed Mohsen Vaziri, Haleh Malek Zadeh and Bita Dadpour; critical revision of the manuscript for important intellectual content: Amir Habibi Tamijani, Arya Hedjazi and Hamideh Ghorbani; statistical analysis: Seyed Mohsen Vaziri, Haleh Malek Zadeh, Bita Dadpour; administrative, technical, and material support: Hamid Khosrojerdi and Arya Hedjazi; study supervision: Arya Hedjazi, Hamid Khosrojerdi and Amir Habibi Tamijani.

Funding/Support: This research was funded by the Iran legal medicine research center.

\section{References}

1. Rehm J, Mathers C, Popova S, Thavorncharoensap M, Teerawattananon Y, Patra J. Global burden of disease and injury and economic cost attributable to alcohol use and alcohol-use disorders. Lancet. 2009;373(9682):2223-33. doi: 10.1016/S0140-6736(09)60746-7. [PubMed: 19560604].

2. Rehm J, Room R, Graham K, Monteiro M, Gmel G, Sempos CT. The relationship of average volume of alcohol consumption and patterns of drinking to burden of disease: an overview. Addiction. 2003;98(9):1209-28. [PubMed: 12930209]. 
3. Rehm J, Kailasapillai S, Larsen E, Rehm MX, Samokhvalov AV, Shield $\mathrm{KD}$, et al. A systematic review of the epidemiology of unrecorded alcohol consumption and the chemical composition of unrecorded alcohol. Addiction. 2014;109(6):880-93. doi: 10.1111/add.12498. [PubMed: 24467748].

4. Gulmen MK, Meral D, Hilal A, Akcan R, Cekin N. Methanol intoxications in adana, Turkey. Toxicol Mech Methods. 2006;16(7):353-7. doi: 10.1080/15376520600616917. [PubMed: 20021007].

5. Lachenmeier DW, Haupt S, Schulz K. Defining maximum levels of higher alcohols in alcoholic beverages and surrogate alcohol products. Regul Toxicol Pharmacol. 2008;50(3):313-21. doi: 10.1016/j.yrtph.2007.12.008. [PubMed: 18295386].

6. Rehm J, Lachenmeier DW. Unrecorded alcohol and lead poisoning. Am J Med. 2013;126(12):e39. doi: 10.1016/j.amjmed.2013.05.019. [PubMed: 24262744].

7. Linderborg K, Salaspuro M, Vakevainen S. A single sip of a strong alcoholic beverage causes exposure to carcinogenic concentrations of acetaldehyde in the oral cavity. Food Chem Toxicol. 2011;49(9):2103-6. doi: 10.1016/j.fct.2011.05.024. [PubMed: 21641957].

8. Ryan R. Safety of Food and Beverages: Alcoholic Beverages. USA: Academic Press; 2014. pp. 364-70.

9. Lachenmeier DW, Taylor BJ, Rehm J. Alcohol under the radar: do we have policy options regarding unrecorded alcohol?. Int J Drug Policy. 2011;22(2):153-60. doi: 10.1016/j.drugpo.2010.11.002. [PubMed: 21242085].

10. Tsakiris A, Kallithraka S, Kourkoutas Y. Grape brandy production, composition and sensory evaluation.J Sci Food Agric. 2014;94(3):40414. doi: 10.1002/jsfa.6377. [PubMed: 24037649].

11. Gil A, Polikina O, Koroleva N, McKee M, Tomkins S, Leon DA. Availability and characteristics of nonbeverage alcohols sold in 17 Russian cities in 2007. Alcohol Clin Exp Res. 2009;33(1):79-85. doi: 10.1111/j.15300277.2008.00813.x. [PubMed: 19018753].
12. McKee M, Suzcs S, Sarvary A, Adany R, Kiryanov N, Saburova L, et al The composition of surrogate alcohols consumed in Russia. Alcohol Clin Exp Res. 2005;29(10):1884-8. [PubMed: 16269919].

13. Popova S, Rehm J, Patra J, Zatonski W. Comparing alcohol consumption in central and eastern Europe to other European countries. Alcohol Alcohol. 2007;42(5):465-73. doi: 10.1093/alcalc/agl124. [PubMed: 17287207].

14. Lachenmeier DW, Samokhvalov AV, Leitz J, Schoeberl K, Kuballa T, Linskiy IV, et al. The composition of unrecorded alcohol from eastern Ukraine: is there a toxicological concern beyond ethanol alone? Food Chem Toxicol. 2010;48(10):2842-7. doi: 10.1016/j.fct.2010.07.016. [PubMed: 20638436].

15. Lachenmeier DW, Sarsh B, Rehm J. The composition of alcohol products from markets in Lithuania and Hungary, and potential health consequences: a pilot study. Alcohol Alcohol. 2009;44(1):93-102. doi: 10.1093/alcalc/agn095. [PubMed: 19033379].

16. Paine A, Davan AD. Defining a tolerable concentration of methanol in alcoholic drinks. Hum Exp Toxicol. 2001;20(11):563-8. [PubMed 11926610].

17. Lachenmeier DW, Rehm J, Gmel G. Surrogate alcohol: what do we know and where do we go?. Alcohol Clin Exp Res. 2007;31(10):1613-24. doi: 10.1111/j.1530-0277.2007.00474.x. [PubMed: 17681034].

18. Coomber K, Miller PG, Livingston M, Xantidis L. Larger regional and rural areas in Victoria, Australia, experience more alcohol-related injury presentations at emergency departments. J Rural Health. 2013;29(3):320-6. doi:10.1111/jrh.12014. [PubMed: 23802934].

19. Silm S, Ahas R. Seasonality of alcohol-related phenomena in Estonia Int J Biometeorol. 2005;49(4):215-23. doi: 10.1007/s00484-004-0240-4. [PubMed: 15578233].

20. Palma M, Barroso CG. Acid-base and precipitation equilibria in wine JChem Edu. 2004;81(1):94. doi: 10.1021/edo81p94. 